\title{
JOURNAL
}

of Health Inequalities

\section{Policy recommendation to members of the Russian Federal Government: Strong tobacco control measures as a key to reducing mortality}

\author{
Anna Louise Barr ${ }^{1}$, Teresa Hall${ }^{2}$, Emilia Holland ${ }^{3}$, Nazla Rafeeg ${ }^{4}$, Silvia Segovia Chacon ${ }^{5}$, Emilie Taymor ${ }^{6}$, \\ Inna Walker ${ }^{3}$, Mateusz Zatonski ${ }^{3,7}$

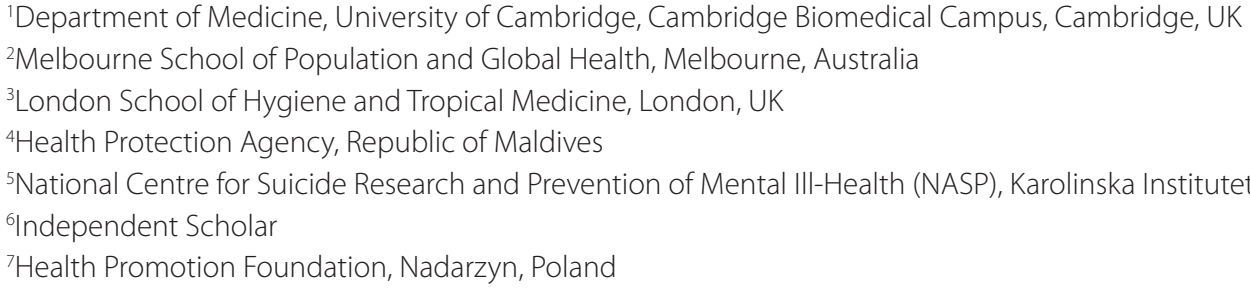

\begin{abstract}
Tobacco-related diseases are among the most significant contributors to Russia’s premature mortality burden. Smoking prevalence has been rising in Russia in the last decades, leading to worsening health and economic outcomes. This policy recommendation to members of the Russian Federal Government suggests that Russia carry out legislative and tobacco control measures including increasing the tax on tobacco products, better enforcement of smoke-free legislation, and the introduction of graphic warning on tobacco products, in order to tackle this public health.
\end{abstract}

KEY WORDS: tobacco control, Russia, premature mortality, policy, smoking.

ADDRESS FOR CORRESPONDENCE: Mateusz Zatoński, London School of Hygiene and Tropical Medicine, Keppel Street, London WC1E 7HT, UK, phone: +44 7415240 171, e-mail: mateusz.zatonski@lshtm.ac.uk

\section{KEY MESSAGES}

- Tobacco-related diseases are among the most significant contributors to Russia's premature mortality burden, independently doubling the mortality risk in the Russian population.

- Smoking prevalence has been rising in Russia in the last decades, leading to worsening health and economic outcomes.

- More effective legislation and tobacco control measures can help reduce Russia’s mortality burden. Options include higher taxes on tobacco products, enforcement of new smoke-free legislation, and the introduction of graphic warning labels on tobacco products sold on the Russian market.

\section{RATIONALE FOR ACTION TOBACCO DEATH TOLL}

Tobacco smoking has been shown to lead to numerous adverse, and frequently fatal, health outcomes. The most important broad categories of tobacco-related medical conditions are cancer ${ }^{1}$, cardiovascular disease $e^{2}$ and respiratory conditions $s^{3}[1-3]$.

Tobacco smoking is the leading preventable cause of morbidity and mortality in the Russian Federation. 
Smoking accounts for $30 \%$ of the crude mortality rate in men and $4 \%$ in women. Smoking-related cancer mortality constitutes as much as $52 \%$ of all cancer mortality in men and 5\% in women. The number of smoking-related deaths in Russia is estimated to be in the region of 400,000 per annum [4]. Smoking has been found to independently double mortality risk in the Russian population [5].

\section{RISE OF SMOKING RATES}

The highest smoking rates in Russia are found in men. Approximately $60 \%$ of men in Russia are smokers [6]. This rate has increased from circa $45 \%$ in the mid1980s [4]. The cause of this increase was the combined effect of political transition and low levels of governmental tobacco control to combat the high levels of targeting by tobacco companies [7].

Rates of smoking in women and children are also increasing. The smoking prevalence in Russian women has more than doubled (from $10 \%$ to $21 \%$ ) over the last 15 years [6]. This rise has been accompanied by the increasingly aggressive targeting of women by transnational tobacco companies with brands such as 'slim' and 'ultra-slim' [8]. The prevalence of smoking in Russian boys (13-15 years) is $30 \%$ and in Russian girls (13-15 years) it is $24 \%$ [4]. The highest smoking rates are found in the least educated segment of the population. Almost $10 \%$ of Russian adults do not believe that smoking causes significant disease and that it is addictive. Almost a quarter of young smokers (aged 15-18) do not believe that smoking is addictive [4].

Over $50 \%$ of Russians are exposed to second hand smoking in public places [4]. Additionally, almost 30\% of youth are exposed to second hand smoke at home [9].

\section{SOARING COSTS OF SMOKING}

Russia is one of the most important markets for transnational tobacco companies [8]. The price of cigarettes is extremely low [10]. Less than $2 \%$ of the cigarettes smoked in Russia are imported. However, $99 \%$ of the tobacco leaf used in the manufacture of cigarettes is imported with a cost to the Russian economy of approximately one billion US dollars in 2008. Less than $2 \%$ of the manufactured cigarettes are then exported leading to a large trade deficit [11].

World Bank estimated in 2003 that the cost of treating conditions related to smoking in Russia was 83 billion rubles for cardiovascular disease and 42 billion rubles for respiratory diseases. These costs were far higher than the revenue from the tax on tobacco which was 20 billion rubles [4].

Research shows that consumers who quit smoking would relocate their spending on groceries, recreation, housing and clothing. Stronger tobacco control policies would therefore aid the Russian economy as workers would be healthier and would be spending in other sectors of the economy [11].

\section{INSUFFICIENT TOBACCO CONTROL MEASURES}

In 2008 Russia acceded to the World Health Organization's Framework Convention on Tobacco Control (FCTC). In September 2010, Prime Minister Vladimir Putin signed the 'Concept of creation of a public policy to combat tobacco consumption from 2010-2015' [12]. This was a first step to combat tobacco use bringing Russia into alignment with the FCTC [4].

Since then Russia has implemented stronger tobacco control measures. In early 2013, Russia has passed a comprehensive tobacco control law, which complies with many provisions of FCTC including health warnings, and adopted stronger smoke-free air laws and advertising restrictions. However, a simulation model (Russia SimSmoke) to examine the effects of tobacco control policies on past and future smoking prevalence and premature mortality in Russia shows that much remains to be done in order to meet the FCTC requirements [6]. Russia also needs to strengthen its current tobacco control strategy in order to tackle the tobacco industry's influences on policy processes and law [9].

\section{POLICY PROPOSALS \\ INCREASE OF TOBACCO PRICES}

A rise of tobacco prices is key to curbing tobacco use in Russia. This can be achieved by increasing tariffs on raw tobacco imported into the country by cigarette manufacturers, as well as increasing tariffs on any product containing tobacco sold or brought into Russia.

Currently tobacco companies take advantage of low import duties for raw tobacco which allow cigarette manufacturers to keep cigarette prices down. Over the last decade income and real wages have increased by $12 \%$ to $16 \%$ annually while real prices for cigarettes have fallen over $40 \%$, making tobacco products increasingly affordable [9].

Studies by the World Bank and the WHO show that the most powerful and cost-effective intervention to curb tobacco consumption is through the use of taxes to raise the price of tobacco related goods on the individual consumer [13]. This inverse relationship between cigarette price and consumption is seen to be stronger in Eastern Europe than Western Europe, where tobacco taxes have already been raised substantially higher [14]. This makes the policy of increased taxation particularly suitable for Russia.

Although in 2011 cigarette taxes were raised to $50 \%$ of retail price in the Russian Federation, this is still far below other European countries. It would therefore be beneficial to follow the recommendations of the International Union Against Tuberculosis and Lung Disease and raise the tobacco tax to $70 \%$ [15].

In proposing raising tobacco taxes we recognise their regressive nature. However, because tobacco price elasticity is higher for people with lower incomes, the tobacco products tax will deter young smokers and people with lower income most effectively from smoking. This 
will contribute significantly to reducing smoking prevalence among the Russian population as a whole [16].

In order to help address the negative implications of a regressive tax - in that it is more harmful to lower income individuals and could therefore potentially increase inequalities if tobacco consumers continue to consume higher priced tobacco products and cut other spending - we propose that the money from the additional tax revenue goes towards tobacco cessation education programs targeted at young and lower income individuals. The tax money can subsidize education programmes in schools about the negative effects of cigarette smoking and smoking cessation programmes in local community centres in low-income neighbourhoods.

\section{ENFORCEMENT OF NEW SMOKE-FREE POLICIES}

As part of Russia's adoption of the FCTC guidelines, a governmental action plan has been established to implement a comprehensive public smoking ban by 2015 . On 1 June 2013, 100\% smoke-free policies were implemented in private offices, educational, cultural, medical and sport facilities, government buildings, elevators and stairwells of apartment buildings, public transport, airports, and all public playgrounds and beaches [17]. On 15 November 2013 fines were introduced for those who did not comply, ranging from 500 to 3,000 rubles (US \$15-US \$90) [18]. From 1 June 2014, a complete smoking bans will be extended to venues of hospitality including restaurants, bars, clubs, cafes, hotels, shopping areas [17]. It is crucial that these new legislation be enforced and policed effectively.

If implemented and enforced correctly these policies can change social norms and views about the dangers of second hand smoke, and smoking in general. This new understanding may translate into alterations to smoking behaviours particularly in the smoker's own personal spaces such as their home and car. The projected effect of these policies is a reduction in the prevalence of male and female smoking by $9 \%$ relative to the scenario in 2015 if no smoke-free laws were implemented, and by $12 \%$ by 2055 [6]. These predictions do not include the additional deaths prevented due to reductions in second hand smoke exposure.

Experiences in other countries have found smoking bans in public places as cost-effective interventions to reduce both active and passive smoking. They affect a high proportion of the population, including vulnerable populations such as women and children. They are particularly effective when implemented with the support of the public. According to reports, prior to the implementation of smoking bans, the majority of respondents supported bans in work places, educational and health care facilities. Support was not as high for a ban in restaurants $(59.1 \%)$ or bars (48.9\%) [4], however the numbers in favour were higher than in some countries where these laws had already been implemented successfully. Public health advertising campaigns which reinforce the messages of the dangers of second hand smoke have appeared to coincide with the implementation of the smoking ban, and should be continued.

Russia is taking important steps towards creating healthy, smoke-free environments and reducing the exposure of non-smokers to harmful second hand smoke. It is crucial that these laws are enforced proactively and consistently across the country to achieve high compliance. Continuous evaluation of compliance by the Ministry of Health through self-reporting, direct observation and government enforcement and compliance records is essential [19]. Civil anti-smoking groups are needed to apply pressure to those local governments or enforcement groups which turn a blind eye to establishments and institutions that do not comply. Additionally local governments should incorporate lessons learnt through the establishment of Sochi, the 2014 host of the Winter Olympics, as a smoke-free city, into its enforcement and compliance mechanisms.

\section{INTRODUCTION OF LARGE, BOLD \\ AND GRAPHIC WARNING LABELS}

Another key measure to reduce tobacco-attributable mortality in Russia is to upgrade the current governmental policy on warning labels to include large, bold and graphic labels concerning the negative health effects of smoking on all cigarette packets. This measure should be adopted immediately with all new packets and with a policy-adoption phase of one year for existing packets. Such labels will encourage smoking cessation, as well as combat smoking initiation.

The efficacy of graphic pictorial warning labels in promoting the adverse health effects of smoking has been demonstrated in studies from Canada [20, 21], Mexico [22], and Spain [23]. This research has highlighted the need to accompany black and white labels with graphic pictures in order to generate sufficient negative emotional activation to discourage from smoking [23].

The adoption of a large, bold and graphic warning label protocol has been estimated to reduce the prevalence and initiation of smoking by $4 \%$ and promote a $10 \%$ increase in cessation rate [6]. This protocol would more than halve the projected initiation and prevalence smoking rates, and double the projected cessation rate of that of the current governmental policy in which warning labels are required to cover $1 / 3$ of the front of packet [6].

A $10 \%$ increase in cessation rate would ease the burden of the large number of existing smokers. The benefit of promoting health knowledge through pictures at the point of sale may access the subset of the population who are less likely to receive health information through traditional media sources (rural, homeless, illiterate). The consequent reduction in tobacco-related disease will reduce the burden on the health services in the country, improve the quality of life of Russians, and improve the productivity of the working age population. 
National funding to support local monitoring of the policy will be crucial in its successful enforcement. Similarly important will be the determination to face legal action against the policy from the tobacco industry, and an ability to evince policy from similar best practice precedents from around the world. Finally, a certain level of government subsidy might be needed to encourage shopkeepers to support the new measure, as their revenue might temporarily decrease until they transition to new products.

\section{DISCLOSURE}

Authors report no conflict of interest.

\section{References}

1. Centers for Disease Control and Prevention. Health Effects of Cigarette Smoking Factsheet 2013. Available from: http://www. cdc.gov/tobacco/data_statistics/fact_sheets/health_effects/ effects_cig_smoking/ (accessed: 10 November 2013).

2. Frew AJ, Holgate ST. Smoking: the dangers. In: Clinical Medicine. $6^{\text {th }}$ ed. Kumar PJ, Clark ML (eds.). Elsevier Saunders 2005; 893.

3. Torres A, Peetermans WE, Viegi G, et al. Risk factors for community-acquired pneumonia in adults in Europe: a literature review. Thorax 2013; 68: 1057-1065.

4. World Health Organisation. Global Adult Tobacco Survey (GATS) Russian Federation 2009 Country Report. Published 2010. Available from: http://www.who.int/tobacco/surveillance /en_tti_gats_ russian_countryreport.pdf (accessed: 26 November 2013).

5. Perlman F, Bobak M. Socioeconomic and behavioral determinants of mortality in post-transition Russia: a prospective population study. Ann Epidemiol 2008; 18: 92-100.

6. Maslennikova GY, Oganov RG, Boytsov SA, et al. Russia SimSmoke: the long-term effects of tobacco control policies on smoking prevalence and smoking-attributable deaths in Russia. Tob Control 2014; 23: 484-490.

7. Stickley A, Carlson P. The social and economic determinants of smoking in Moscow, Russia. Scand J Public Health 2009; 37: 632 639.

8. Holmes D. Smoking in Russia: will old habits die hard? Lancet 2011; 378: 973-974.

9. Lunze K, Migliorini L. Tobacco control in the Russian Federation - a policy analysis. BMC Public Health 2013; 13: 64.

10. Danishevski K, GilmoreA, Mckee M. Public attitudes towards smoking and tobacco control policy in Russia. Tob Control 2008; 7: 276-283.

11. Merrill R, Castleton R, Lindsay G. Sectors of the Russian economy that would benefit from reduced cigarette sales. Tob Control 2009; 18: 505-508.

12. Government order of the Russian Federation. Concept of creation of a public policy on combating tobacco consumption from 2010-2015. Available from: http://global.tobaccofreekids.org/files/pdfs/en/Russian_Concept_on_Tobacco_en.pdf (acceded 9 November 2013).

13. World Health Organisation. Guidelines for implementation of the WHO FCTC, 2011.

14. Gallus S, Schiaffino A, La Vecchia C, et al. Price and cigarette consumption in Europe. Tob Control 2006; 15: 114-119.
15. Ross HZ, Shariff S, Gilmore A. Economics of Tobacco Taxation in Russia. International Union Against Tuberculosis and Lung Disease, Paris 2008.

16. World Bank: Tobacco Control in Developing Countries. 2000.

17. World Lung Foundation. World Lung Foundation congratulates Russian government on new national tobacco control law. Available from: http://www.worldlungfoundation.org/ht/display/ ReleaseDetails/i/23180/pid/6858 (accessed: 29 October 2013).

18. RIA Novosti. Fines for smoking in public in Russia take effect. RIA Novosti, Moscow 2013.

19. International Agency for Research on Cancer, IARC Handbooks of Cancer Prevention: Methods of Evaluating Tobacco Control Policies. WHO, Geneva 2008.

20. Hammond D, Fong GT, McDonald PW, et al. Graphic Canadian cigarette warning labels and adverse outcomes: evidence from Canadian smokers. Am J Public Health 2004; 94: 1442-1445.

21. Hammond D, Fong GT, McDonald PW, et al. Impact of the graphic Canadian warning labels on adult smoking behaviour. Tob Control 2003; 12: 391-395.

22. Thrasher M, Allen B, Reynales-Shigematsu LM, et al. Análisis del impacto en fumadores mexicanos de los avisos gráficos en las cajetillas decigarros [Analysis of the impact of graphic warnings on cigarette packs on Mexican smokers]. Salud Pública de Mexico 2006; 48: S65-S74.

23. Crespo A, Barrio A, Cabestrero R, et al. Cognitive processing and assessment of anti-smoking combined warning labels proposed by the European Commission: An empirical study with a Spanish sample. Psychology in Spain 2008; 12: 26-36 